1 Universidade Federal do Recôncavo da Bahia (UFRB) - Cachoeira (BA), Brasil.

Orcid: https://orcid org/0000-0002-9455$843 \mathrm{X}$

marciarocha.jor@gmail.com

2 Universidade Federal da Bahia (UFBA), Instituto de Saúde Coletiva (ISC) Salvador (BA), Brasil. Orcid: https://orcid. org/0000-0001-73403132

lirangel@ufba.br

3 Fundação Oswaldo Cruz (Fiocruz) - Salvador (BA), Brasil.

Orcid: https://orcid. org/0000-0001-84382445

ambrotas@gmail.com

\section{A saúde do idoso na televisão: prescrição de estilo de vida saudável}

\author{
The health of the elderly on television: healthy lifestyle prescription
}

Márcia Cristina Rocha Costa', Maria Ligia Rangel Santos², Antonio Marcos Pereira Brotas ${ }^{\mathbf{3}}$

DOI: 10.1590/0103-11042018S218

RESUMO Este artigo apresenta a análise do enquadramento (framing) da saúde do idoso em um programa da série 'Ser Saudável', da TV Brasil, e também em uma edição do programa 'Bem Estar', da TV Globo. Adota-se como caminho teórico-metodológico a ideia de frame como 'pacotes interpretativos' partilhados socialmente, que produzem sentidos, a partir de determinadas perspectivas. Identifica-se a hegemonia dos quadros Técnico-Científico e Comportamento e Responsabilidade Individual na abordagem do tema, tanto numa emissora não comercial quanto na TV comercial, enquanto os quadros Sociocultural e Ambiental e a Política Pública emergem tangencialmente. Dessa forma, reforça-se a ideia de uma velhice bem-sucedida para quem segue as recomendações médicas e faz escolhas saudáveis, sem levar em conta os determinantes sociais e o papel do Estado na promoção da saúde do idoso.

PALAVRAS-CHAVE Saúde do idoso. Mídia audiovisual. Televisão.

ABSTRACT This article presents the analysis of the framing of the health of the elderly on a program of the series 'Ser Saudável', on TV Brasil, and also in an edition of the program 'Bem Estar', on TV Globo. It adopts as theoretical-methodological path the idea of frame as 'interpretative packages' socially shared, which produce senses, from certain perspectives. It identifies the hegemony of Technical-Scientific and Behavioral and Individual Responsibility frameworks in addressing the issue, both in a non-commercial broadcaster and in commercial TV, while the Sociocultural and Environmental and Public Policy frameworks emerge tangentially. This reinforces the idea of a successful old age for those who follow the medical recommendations and makes healthy choices, without taking into account social determinants and the role of the State in promoting the health of the elderly.

KEYWORDS Health of the elderly. Video-audio media. Television. 


\section{Introdução}

A população idosa, por se tratar do grupo social mais afetado pelas doenças crônico-degenerativas, diante do aumento da expectativa de vida do brasileiro', é uma parcela significativa de consumidores em potencial dos produtos e serviços que o mercado da saúde oferece, em nome de uma vida longeva e saudável. A mídia, enquanto uma das instituições culturais mais poderosas do sistema capitalista, também tem, nesse apreciador idoso, um filão de audiência: 26,1 milhões de pessoas acima dos 60 anos, segundo o Instituto Brasileiro de Geografia e Estatística (IBGE) ${ }^{2}$.

O Estatuto do Idoso, criado pela Lei federal $\mathrm{n}^{\circ} 10.741$, de $1^{\circ}$ de outubro de 2003 , garante direitos fundamentais à integridade física, mental, social, moral, intelectual, com punição à violência e discriminação às pessoas idosas. A Política Nacional de Saúde da Pessoa Idosa, instituída pela Portaria ${ }^{\circ}$ 2.528 , de 2006, ainda não alcançou a sua finalidade primordial de "recuperar, manter e promover a autonomia e a independência dos idosos, direcionando medidas coletivas e individuais de saúde"3.

Estudos evidenciam desigualdades no acesso aos serviços de saúde ${ }^{4,5}$, bem como às medicações para o tratamento de saúde 6 , de modo que a maioria da população as adquire através de seus próprios recursos e, frequentemente, entre os idosos, mediante automedicação $0^{7}$. Apontam, também, a existência de inúmeras situações de humilhação, insultos e até mesmo maus tratos no cotidiano dessa população. A ausência dessas políticas deixa recair "sobre a família a responsabilidade pelo cuidado para com as pessoas idosas, sem ser dado à mesma um preparo para tal função"8(283).

Por sua vez, o enquadramento da mídia, resultado da interpretação partilhada socialmente, associa a velhice saudável a uma responsabilidade sobre si mesmo e a fatores biológicos, ignorando aspectos sociais e ambientais. Neste artigo, analisa-se o enquadramento da saúde em dois programas da televisão aberta que abordaram o tema: uma edição da série 'Ser Saudável' (TV Brasil) e uma edição do 'Bem Estar' (TV Globo). Mesmo em se tratando de duas propostas editoriais diferentes, tanto no formato quanto na periodicidade, a análise identificou os quadros hegemônicos e a dinâmica dos seus agentes na ação comunicativa, permitindo apontar semelhanças tanto na abordagem do tema na TV Brasil, que está no campo público, quanto na TV Globo, que é comercial.

Nesse contexto, para Martín-Barbero ${ }^{9}$, a televisão tem papel fundamental na difusão de discursos e seus sentidos, especialmente pela sua 'cotidianidade familiar', que chega a uma vasta audiência. Para o autor, os meios, enquanto espaços de mediação, produzem o que está na cultura. O público se identifica com os produtos da indústria cultural, não por imposição dos veículos de comunicação a uma audiência passiva, mas na medida em que ela se reconhece nesses produtos. A hegemonia, no sentido gramsciano usado por Martín-Barbero 9 , está presente no cotidiano das pessoas e nos usos sociais da mídia. Não se trata de hegemonia pela dominação, mas pela disputa de sentidos, reconhecida pelo consenso do público. São relações de poder em que o não hegemônico pode até aparecer, mas quem dirige é a cultura hegemônica, feita de cumplicidade e sedução.

\section{A saúde do idoso na mídia}

Ao analisar as representações do idoso na década de 1990, Debert ${ }^{10}$ observa que há imagens tão dramáticas quanto produtivas dos idosos, dos abandonados em asilos e sofridos aposentados, em oposição aos produtivos e ativos que participam de grupos de convivência e universidades para a terceira idade. Ao mesclar essas imagens, 'aparentemente antagônicas', a autora percebe uma 'reprivatização da velhice', responsabilizando o indivíduo pelos seus dramas, já que este não teria se cuidado nem buscado atividades 
motivadoras. Nesse contexto, a mídia desfaz imagens associadas à velhice, sugerindo comportamentos e estilos de vida saudáveis para quem não se sente velho, e que são mais aceitos pela sociedade.

Abordar a velhice na experiência contemporânea é descrever um contexto em que as imagens e os espaços abertos para uma velhice bem-sucedida não levam necessariamente a uma atitude mais tolerante com os velhos, mas sim, e antes de tudo, a um compromisso com um tipo determinado de velhice positivo ${ }^{\mathbf{1 0}}$

O aumento da expectativa de vida e longevidade na terceira idade pode trazer novos signos para a velhice, e a juventude é um bem possível em qualquer idade, desde que se adote um estilo de vida adequado para uma velhice ativa, produtiva, com saúde e bem-sucedida. Para essa crescente parcela da população brasileira, há um mercado de produtos e serviços. Ao reforçar a responsabilidade individual pela saúde e a possibilidade de se manter jovem seguindo determinadas lógicas de consumo, a mídia não contempla os vários tipos de velhice, não contribui para a percepção de que nem todos poderão ter acesso a essas escolhas, e ainda exclui o papel do Estado e da própria sociedade para com os seus idosos.

\section{$O$ individual e o coletivo}

A prioridade do individual sobre o coletivo se apresenta na mídia submetida a uma lógica comercial pouco interessada na promoção da saúde e, portanto, distante do entendimento de que a saúde também é um bem coletivo. Enquanto o conteúdo informativo dissemina o risco de determinados comportamentos, como comer alimentos gordurosos e sal em excesso ou ser sedentário, a propaganda nas diferentes mídias expõe o público ao risco de consumir alimentos industrializados, ricos em produtos químicos e pobres em nutrientes, sem se preocupar com as consequências que esse estímulo ao consumo poderá trazer ao corpo individual e coletivo.

A própria expressão 'sua saúde', largamente usada nos conteúdos sobre saúde das mídias, já sinaliza o sentido de um corpo individual que será tratado individualmente, sob a intervenção de medicamentos, exercícios ou cirurgias, estéticas ou não. Embora seja um fato coletivo, em sua emissão, as mensagens sobre saúde e doença não criam no receptor, na maioria das vezes, esse mesmo sentido, pois a audiência é tratada como um conjunto de consumidores individuais de produtos. Para Lefèvre"1, a saúde como fato coletivo deveria apresentar conteúdo com base na promoção da saúde, abrigando outros modelos, não consumistas e coletivos, além do biomédico.

\section{Metodologia}

Para o estudo dos enquadramentos, é adotado o conceito de frames (quadros) midiáticos, entendidos como 'pacotes interpretativos', construídos e partilhados socialmente, cuja ideia organizadora central conduz a um sentido. Eles não são estáticos nem individuais, envolvendo fontes, produtores e audiência na construção de significados ${ }^{12-16}$. Portanto, os quadros não são determinados diretamente da mídia para a audiência, mas resultam de um complexo processo de interlocuções e estão associados a um fenômeno cultural. Ao pesquisador, cabe identificar o que é dito e o que é silenciado, bem como a combinação de quadros.

Optou-se pela abordagem dedutiva, em que os quadros surgem após uma revisão da literatura e análise do conteúdo, realizada com a leitura textual e visual dos programas. Palavras-chave e expressões frequentes, imagens e argumentos recorrentes, em cada programa, apontaram dispositivos de enquadramento, que levaram aos dispositivos de raciocínio, entendidos como os discursos 
explícitos, ou implícitos, que justificam e/ ou apontam causas e consequências. Como afirma Entman 17(52):

Enquadrar é selecionar alguns aspectos da realidade percebida e torná-los mais salientes em um texto comunicativo, de modo a promover uma definição particular do problema, uma interpretação causal, uma avaliação moral e/ou recomendação de tratamento para o item descrito.

Na tarefa de identificação dos quadros, buscou-se a relação lógica entre os dispositivos de enquadramento e os dispositivos de raciocínio, ou seja, elementos constitutivos das mensagens que, agrupados, formam um padrão numa amostra, a moldura que envolve o enquadramento. Assim, chega-se a quatro frames, embalados por pressupostos enraizados na cultura, cujos significados resultam da ação social18:

1 - Técnico-Científico: aponta as explicações sobre a doença e suas manifestações, mostrando a importância da prevenção, de fazer exames e seguir o tratamento recomendado pelos profissionais da saúde, especialmente médicos e pesquisadores da área da saúde, que apontam: a legitimidade da ciência médica, a importância do médico, o contraponto entre os mitos do senso comum e as verdades da medicina.

2 - Comportamento e Responsabilidade Individual: destaca a importância da alimentação balanceada e da atividade física na rotina, como uma responsabilidade individual, sem levar em conta aspectos sociais, econômicos, ambientais. Responsabiliza o indivíduo pelas consequências dos seus problemas de saúde, sem questionar o papel do Estado ou do mercado.

3 - Política Pública: acentua a saúde como direito do cidadão, um bem coletivo, e o papel do Estado na organização, no monitoramento e na avaliação da saúde.

4 - Sociocultural e Ambiental: aponta a relação entre a saúde e o contexto social, cultural, econômico, ambiental. A saúde é pensada a partir das condições de vida e trabalho da população.

\section{Enquadramento da saúde do idoso no episódio da série 'Ser Saudável'}

O episódio 'Saúde do Idoso', exibido durante a série 'Ser Saudável', atualmente em reprise na TV Brasil, propõe que o envelhecimento ativo é o caminho para ser saudável, mas que é preciso se prevenir para evitar ou reduzir o impacto das doenças na velhice. Essa proposta está em consonância com o quadro Técnico-Científico, acionado como suporte de uma avaliação moral: quem não se cuida, não se mantém ativo, pode ter uma velhice cheia de problemas, como apontam os dados da epidemiologia, baseada em um discurso de risco e probabilidades, que perpassam a construção da narrativa, principalmente no discurso médico.

Expressões como 'procure o médico' e ‘o médico que descobriu' ressaltam a importância desse profissional e sua valorização em relação aos outros profissionais da saúde. Trata-se de uma racionalidade médica cada vez mais fragmentada, em que o corpo é medicalizado, submetido a exames, tecnologias e tratamentos diversos, que estabelecem necessidades de consumo em nome da saúde e da cura, favorecendo corporações que lucram com a doença.

Em uma cultura midiática, em que a 'mercadoria informacional'19 ganha um valor de troca e o individual se sobrepõe ao coletivo, a ênfase no médico demonstra a ressonância do quadro Técnico-Científico, até mesmo em contextos que favoreceram a exposição de quadros não hegemônicos, desvinculados de 
aspectos biológicos e voltados para o social e o público, como se percebe na abordagem sobre o grupo social idoso no discurso dos diferentes atores da ação comunicativa.

[Médica/apresentadora] - Uma coisa que o senhor tá falando que é muito importante, assim, o idoso, muitas vezes, por ter outros problemas de saúde, acaba se automedicando e tendo outras complicações ainda relacionadas com remédio. Então, é importante que todo idoso tenha 'o seu médico de referência' pra conversar a respeito das medicações que são realmente necessárias, assim, ser tomadas.

[Médico/apresentador] - Então faz uma visita ao médico anual, que é um médico...

[Therezinha Groth - aposentada] - Anual. Eu tenho um médico, sempre o mesmo, né? Daí ele pede pra eu ir pros outros que precisa. Aquele que tem lá que faz colonoscopia, daí eu vou também no ginecologista, que também vou anualmente.

[Médico/apresentador] - E quando é que a senhora descobriu o problema da pressão?

[Therezinha] - 'Isso foi o médico que descobriu', porque eu sempre tenho que... Regularmente, 'eu faço check-up', né? E aí ele constatou, e aí eu comecei a tomar. (Programa da série 'Ser Saudável', exibido em 29 de setembro de 2012, na TV Brasil).

Nas entrevistas entre os médicos/apresentadores e os personagens, a referência ao médico foi apontada como o caminho para resolver não só as desordens do corpo, mas, também, os problemas em manter uma sexualidade ativa, associando os quadros Sociocultural e Técnico-Científico.

[Médica/apresentadora] - 'E é importante, também, que o idoso mantenha uma sexualidade ativa'. É muito saudável que isso aconteça e, aquelas 'pessoas que têm dificuldade, também é interessante que busque atendimento médico e recursos, pra resolver', porque hoje em dia isso fica mal resolvido entre os casais. (Programa da série 'Ser Saudável', exibido em 29 de setembro de 2012, na TV Brasil).

O destaque para o papel da categoria médica na proteção da saúde e na prevenção de doenças, para enfrentar o rápido envelhecimento da população brasileira, já se apresenta na escolha das fontes especializadas para discutir o tema: dois geriatras e uma professora de educação física, a qual só aparece na narrativa uma vez, concentrando os depoimentos dos especialistas na voz oriunda do campo da medicina. Dessa forma, observa-se, no depoimento abaixo, do geriatra Moriguchi, uma prioridade para a intervenção médica, ainda que as palavras prevenção, promoção e social façam uma combinação entre os quadros TécnicoCientífico, Política Pública e Sociocultural e Ambiental. Nesse contexto, o quadro Técnico-Científico reduz a questão do envelhecimento aos aspectos de prevenção e controle de doenças, enquanto os quadros Política Pública e Sociocultural e Ambiental apenas fazem uma referência superficial à promoção da saúde e ao Estatuto do Idoso, sem proposições ou associação com determinantes sociais.

[Dr. Emílio Moriguchi - geriatra e professor - Unisinos] - O envelhecimento da população brasileira é um dos envelhecimentos mais rápidos do mundo. Só pra ter uma ideia, enquanto um país como França teve 200 anos pra duplicar o número de idosos e teve tempo pra se preparar, tanto do ponto de vista econômico e social quanto político, o Brasil vai duplicar o número de idosos em 35 anos. Ou seja, nós temos uma estrutura que, infelizmente, ainda não está preparada pra enfrentar essa duplicação do envelhecimento da população, não somente do ponto de vista social, mas, também, do ponto de vista político e econômico. As políticas públicas para promoção de saúde na terceira idade estão começando. 
O marco, certamente, foi o estatuto do idoso, que deu destaque pro idoso, e agora nós temos vários movimentos, a Sociedade Brasileira de Geriatria e Gerontologia e também nas sociedades médicas de outras áreas, como cardiologia, neurologia, para focar na prevenção de doenças relacionadas ao envelhecimento e também o seu tratamento mais adequado. (Programa da série 'Ser Saudável', exibido em 29 de setembro de 2012, na TV Brasil).

Ao tratar de um grupo social, como o idoso, a proeminência do quadro Comportamento e Responsabilidade Individual surge nas interlocuções entre os médicos/apresentadores e os personagens - dois idosos ativos, que trabalham e cuidam bem do corpo. Um deles, atleta de maratona aos 70 anos. Os personagens assumem a exposição desse quadro, associado ao quadro Sociocultural e Ambiental, quando falam de suas concepções de saúde como um estilo de vida que requer, entre outras condicionantes, boa alimentação e atividade física. Os trechos do programa mostram, abaixo, a exposição do quadro Comportamento e Responsabilidade Individual como um compromisso diário na rotina dos personagens, assim como as suas atitudes em busca de uma velhice bem-sucedida.

[Médico/apresentador] - Com que regularidade que a senhora faz atividade física?

[Therezinha] - A regularidade é toda semana, quatro vezes.

[Médico/apresentador] - Quatro vezes por semana.

[Therezinha] - Isso! É regular, é de manhã. De manhã, sempre. Eu saio de casa 7 h30 e volto $10 h 30$.

[Médico/apresentador] - O ponto chave pra que a atividade faça bem pro coração, pra que faça efeito, é regularidade e uma certa intensidade, que a gente recomenda que seja moderada, adaptada à pessoa, e que seja, pelo menos, 30 minutos por dia.

[Therezinha] - Ser saudável é praticar tudo o que manda, por exemplo, melhora a qualidade de vida, fazer exercícios físicos, boa alimentação, fazer grupos, participar de grupos, não ficar sozinha, ter atividades, não só físicas, mas também atividade intelectual.

[Antônio] - Ser saudável tem que haver disciplina, alimentação, respeitar os limites da própria vida. E pra mim seriam esses os indicadores pra ser saudável aos 70 anos. (Programa da série 'Ser Saudável', exibido em 29 de setembro de 2012, na TV Brasil).

O programa 'Saúde do Idoso', apesar de seguir a mesma estrutura narrativa dos demais episódios da série e ter predominância de quadros Técnico-científico e de Responsabilidade Individual, favoreceu a exposição do quadro não hegemônico, o Sociocultural e Ambiental, ao se desviar do tema da superação da doença para a abordagem de um grupo social (idosos). A presença desse quadro no programa 'Saúde do Idoso' se evidencia desde a abertura do episódio, em que a apresentação dos personagens não faz referência a qualquer doença, mas a um grupo social, representado por uma velhice produtiva, ativa, feliz e bem-sucedida. As imagens reforçam a relação entre ser saudável e os contextos social, cultural e familiar dos personagens, que se apresentam em diferentes situações do cotidiano: dona Therezinha dirigindo, arrumando o cabelo no espelho, brincando com a neta ou tocando acordeon, assim como o vigor físico de seu Antônio fazendo atividade física na academia, exibindo os seus troféus como atleta e numa reunião familiar.

Apesar da ênfase na vida social e na autonomia do idoso, o quadro Comportamento e Responsabilidade Social está presente no discurso de práticas que devem ser seguidas por aqueles que não negligenciam o seu 
corpo e, consequentemente, a sua saúde. Assim, o sociocultural aparece dependente da responsabilidade individual. As imagens inseridas exibem idosos dançando, no computador, jogando com os amigos. Porém, essa imagem do idoso ativo e produtivo depende de uma atitude do mesmo, sem levar em conta o planejamento de espaços públicos e políticas públicas que atendam a essas necessidades da terceira idade.

A atividade física, como recomendação dos profissionais da saúde para uma velhice saudável, é seguida à risca pelos personagens do programa, nos depoimentos e nas imagens, que exibem não só dona Therezinha e seu Antônio, como grupos de idosos praticando atividade física. Essa responsabilidade de cuidar do corpo é justificada pelo quadro Técnico-Científico, para mostrar a importância da prevenção de problemas do corpo, e, também, pelo quadro Sociocultural, já que a atividade em grupo é um suporte social para o idoso. Nessa associação de quadros, o Sociocultural e Ambiental aparece em posição subordinada.

[Suzana Wolf - professora de educação física - Unisinos] - [...] o exercício físico significativamente melhora a qualidade do sono do idoso, melhora também a diminuição de dores articulares, natural dessa fase da vida. Então, o idoso tem uma maior lubrificação, uma maior oxigenação do cérebro. E também estudos apontam para a melhora da memória do idoso, visto que o exercício também facilita toda a circulação sanguínea do corpo e do cérebro. A prática de atividade física com idosos tem que ser observada, que ela é mais satisfatória quando ela é observada em grupo, porque o idoso, por natureza, tem muitas perdas de familiares, de amigos, perdas, econômicas. E, ao entrar num programa de atividade física em grupo, ele consegue ressignificar essa sua vida, esses seus amigos, esse seu grupo social. Portanto, recomenda-se que, além do exercício físico, este grupo seja um componente de apoio, de suporte social para esse idoso. (Programa da série 'Ser Saudável', exibido em 29 de setembro de 2012, na TV Brasil).
A exposição do quadro Sociocultural e Ambiental surge, inicialmente, nos relatos de apresentação dos personagens, mas não se impõe na narrativa do episódio 'Saúde do Idoso', prevalecendo a sua associação com outros quadros, geralmente para justificar e/ou fortalecer o argumento dos quadros Técnico-Científico e Responsabilidade Individual. Excetuam-se as situações em que o quadro Sociocultural e Ambiental é acionado para apresentar uma questão cultural mais ampla, que necessita de uma intervenção do Estado, justificando o apoio e a subordinação do quadro Política Pública, que teve três ocorrências registradas neste episódio.

[Médica/apresentadora] - Os idosos, como qualquer outra pessoa, precisam ser respeitados. Preconceito e violência contra pessoas mais veIhas são recorrentes em nossa sociedade e precisam ser combatidos. Você pode acessar o estatuto do idoso no site do Ministério da Saúde e saber todos os direitos da pessoa na terceira idade. (Programa da série 'Ser Saudável', exibido em 29 de setembro de 2012, na TV Brasil).

Os médicos/apresentadores foram os principais responsáveis por acionar o enquadramento Sociocultural e Ambiental, sem a associação com os outros quadros. Foi no quadro fixo Papo Médico que se abordou, pela primeira vez no programa, a necessidade de planejar espaços públicos, pensando nos idosos de uma forma mais abrangente.

[Médico/apresentador] - Com relação à terceira idade, a gente vê uma tendência clara a que, cada vez mais, a proporção de idosos na sociedade vai ser maior, vai ser mais importante. Então a gente tem que começar a planejar, pensar os espaços públicos, os espaços em geral, pra essas pessoas que às vezes têm limitações diferentes. São pessoas com necessidades especiais, muitas vezes, né? Mas a gente tem que superar essa noção de que a pessoa, por ser idosa, não pode ser ativa ou não é tão produtiva. (Programa da série 'Ser Saudável', exibido em 29 de setembro de 2012, na TV Brasil). 
Dentro desse contexto, o episódio sobre a saúde do idoso na série 'Ser Saudável' traz contribuições quando apresenta personagens com autonomia e independência, convivendo com o declínio de algumas funções do corpo, como o paladar, a visão ou a queda de cabelo, mas não contempla as determinantes sociais quando foca a sua abordagem numa velhice bem-sucedida, baseada em exemplos distantes da realidade de muitos idosos brasileiros.

\section{Enquadramento da saúde na edição do programa 'Bem Estar', da TV Globo}

O programa 'Bem Estar', da TV Globo, é exibido diariamente desde 2011, abordando temas diversos da saúde. Foi escolhida para análise a edição do dia 27 de novembro de 2015 , por estar entre os vídeos mais vistos no tema saúde do idoso, cujo título de apresentação do conteúdo no site do programa - 'idosos que iniciam atividade física têm aumento na expectativa de vida' - chama a atenção para aspectos também abordados no episódio da série 'Ser Saudável', como atividade física e longevidade. Nesse sentido, o quadro hegemônico Comportamento e Responsabilidade Individual foi explicitamente o mais acionado, desde a abertura do programa, em que as imagens de idosos fazendo exercícios e dançando reforçam o discurso da responsabilidade e da negligência das pessoas com relação à saúde.

A palavra desculpa está presente em toda a narrativa, não só na fala da apresentadora e das fontes especialistas no estúdio como nas imagens persistentes de placas com a palavra desculpa, apontando os motivos que as pessoas 'inventam' para não fazer atividade física. Todos os agentes envolvidos na ação comunicativa - fontes especialistas, fontes personagens, apresentadores e repórteres - acionam o quadro Comportamento e Responsabilidade Individual, na maioria das vezes, fazendo a associação com o quadro Técnico-Científico, ressaltando os benefícios de quem segue as recomendações médicas e cuida da sua saúde.

Apresentadora: Bom dia, bom dia! Hoje o 'Bem Estar' vai derrubar de uma a uma as 'desculpas' que a gente usa pra não fazer atividade física. Então eu queria começar perguntando ao doutor Leandro... essa daqui é a mais comum: 'eu tenho 'dor' nas juntas, então não vou fazer'. Isso serve como 'desculpa?' (imagem de placa escrito 'DESCULPA: dor nas juntas').

Dr. Leandro: De forma alguma! De fato, essa é uma das desculpas mais comuns, né? Quem tem dor nas juntas tem que descobrir a causa. O primeiro passo é procurar o seu médico pra descobrir a causa da dor. Uma vez descobrindo a dor, as mais comuns são desgaste nas juntas, lombalgia por causa de uma posição. Uma vez descoberta a causa, o exercício vai ajudar muito, muito. $O$ exercício acaba liberando alguma substâncias que nos dão prazer e reduzem a dor, né?

Ana: muitos foram os passos que você já deu na vida, não é mesmo? E aí, quando você para e olha pra trás, toma até um susto de quantos anos já se passaram. Será que ainda dá tempo de se cuidar? Dá, sim. E eu vou mostrar pra você agora. Vem comigo!

Apresentadora: O cardiologista Leandro Echenique e o geriatra Carlos André Freitas dos Santos vão te ajudar a ficar igual ao seu Romildo (imagem de idoso fazendo exercícios com bola).

Romildo: Agora eu sou 10 pra cuidar da minha saúde! (Trechos do Programa 'Bem Estar', exibido em 27 de novembro de 2015).

Palavras e expressões, como qualidade de vida, grupo, vitalidade, emprego, vida, remetem ao quadro Sociocultural e Ambiental, que surge no contexto da narrativa de forma tangencial, subordinado ao 
quadro Comportamento e Responsabilidade Individual. Ou seja, a avaliação moral é: se você não se cuidar, não fizer atividade física, não se alimentar direito, você vai ter uma velhice cheia de dor. No trecho abaixo, a recomendação do programa, para uma telespectadora que tem uma rotina exaustiva de trabalho, passa ao largo de determinantes sociais da saúde, sem questionar o papel das empresas ou do Estado.

Apresentadora: [...] A gente tem um comentário na nossa tela interativa. Vamos dar uma olhada aqui. Vamos lá, Gislaine: 'tenho 40 anos e dois empregos. Trabalho das $5 \mathrm{~h}$ da manhã ate às $22 \mathrm{~h}$, hora em que vou dormir. Tenho dores nas juntas. Já pensei em fazer hidroginástica, mas me resta apenas o domingo. O que eu faço? Me ajudem. Compensa fazer exercício uma vez por semana?'. Tem muita gente como a Gislaine, muita gente.

Dr. Carlos: Muita gente. E não só uma jovem de 40 anos, mas também idosos, que às vezes trabalham e não têm tempo. Então, você pode fazer atividade física levando cachorro pra passear subindo escada e não usando o elevador, você pode descer no ponto de ônibus um quarteirão antes, então você pode otimizar a atividade física no seu dia a dia. Não precisa fazer só exercício regrado, supervisionado, orientado. Então, isso já vai fazer diferença. Se ela sair do sedentarismo, ela já vai ter benefícios.

Apresentadora: Já vai ter mais qualidade de vida.

Dr. Carlos: Não tenha dúvida.

O enquadramento Política Pública praticamente não foi acionado em toda a narrativa sobre a saúde do idoso nessa edição. Houve apenas uma referência à vacina anual, mas nenhuma menção ao serviço saúde ou à gratuidade da vacina oferecida pelo Sistema Único de Saúde (SUS). Essa informação só aparece para valorizar o quadro TécnicoCientífico e, consequentemente, dar suporte ao enquadramento Comportamento e Responsabilidade Individual. Assim, a narrativa se caracteriza pela associação dos quadros hegemônicos, na maioria das vezes, usando a referência médica, a doença e a prevenção para realçar as vantagens do cuidado individual da saúde. Dessa forma, a abordagem não apenas reflete sentidos partilhados socialmente, mas, também, os interesses do mercado da saúde, que encontra na mídia uma aliada.

Dr. Carlos: O exercício físico pra quem tem 'pressão alta' é benéfico. É muito comum o paciente estar tomando dois, três medicamentos e, quando começa a fazer um exercício regular, a gente consegue até reduzir o número de remédios que ele toma. Então, é importante que ele tome o 'medicamento', que ele tenha o 'acompanhamento médico adequado, porém, a dieta saudável e o exercício físico regular são extremamente importantes, tão importantes quanto o medicamento'.

Apresentadora: [...] É sobre isso que a gente vai falar agora, sobre uma 'pesquisa' feita aqui em são Paulo, que o Dr. Carlos estava me contando, que mostrou que 'as mulheres que fazem mais atividade física têm mais anticorpos no corpo', né?

Dr. Carlos: Então, foram separados dois grupos de idosas, um que fazia atividade física regularmente e outro grupo que não fazia. Elas foram vacinadas com 'a vacina da gripe, a vacina do idoso', que tem todo ano, e 'o grupo que fazia atividade física teve uma produção de anticorpos contra o vírus da gripe muito superior àquelas que não faziam atividade física'.

A palavra dor, por exemplo, faz frequentemente referência ao enquadramento TécnicoCientífico, apontando as consequências para quem não segue o tal estilo de vida saudável recomendado pelos especialistas, especialmente os médicos, que têm voz predominante em todo o programa, nas falas de um cardiologista e um geriatra presentes no estúdio, que ganham o reforço da apresentadora, do repórter e dos personagens entrevistados. 
Apresentadora: Ele convive com a dor, mas com a atividade física vai melhorar a qualidade de vida porque ele vai sentir menos dor.

Dr. Leandro: Sem dúvida, vai sentir menos dor. E no idoso, o que acontece é que, ao longo do tempo, vai reduzindo a massa muscular e ele vai perdendo força. Isso piora a dor, e o exercício vai ajudar em todos esses aspectos.

Repórter Ana: Como é que é? Consegue requebrar até o chão?

Maria: Requebro até o chão.

Repórter Ana: E não dói nada?

Maria: Não dói nada. Antes doía, agora não dói mais.

Outros profissionais da saúde, como psicóloga e educadora física, também participam da narrativa, fazendo a relação entre corpo e mente em reportagens apresentadas durante o programa. Além de ter uma participação bem menor dentro do programa, considerando que são falas editadas numa reportagem, e não com espaço ao vivo, como ocorre com os convidados médicos do estúdio, essas falas focam prioritariamente no biológico, abordando questões de memória, raciocínio, capacidade motora e de cognição.

Psicóloga Cleide: Todos os brinquedos são feitos para estimular a 'cognição'. O que é a cognição, falando de uma forma bem sucinta? É a capacidade de aprendizado. Por que eu uso muitas coisas infantis? Porque são bonitas.

Voz de Ana: Quebra-cabeças de todos os jeitos, jogos, desenhos, até pega-varetas.

Maria: Ah, porque parece assim: 'ah, vai lá fazer joguinho de 'memória', encaixar', mas é tão importante você ver que, nossa, como você custa a montar um negocinho desse, sabe? Porque você tem que parar pra pensar.
Psicóloga Cleide: Não demorar muito numa tarefa dá a sensação de competência, 'eu consigo terminar'. Eu mando essa mensagem para o 'cérebro', que eu sou capaz.

Voz de Ana: Mas essa não é uma aula convencional para a terceira idade. Eles estão aqui para aprender sobre a 'saúde do corpo e da mente'. No começo, ao som do apito, é só bater a bola. Depois, os comandos viram coreografias (idosos fazendo gestos sincronizados com a bola).

Cristiane: A primeira parte é 'neuromotora', que é focada em desenvolver novas sinapses de neurônios. A gente trabalha tempo de reação, trabaIhamos 'memória, raciocínio'.

Ao apresentar, numa reportagem do programa, o clube da longevidade, a repórter dá o tom do enquadramento da matéria, reforçado por personagens que também assumem o ônus e o bônus da gestão de sua saúde. O quadro Sociocultural e Ambiental só aparece subordinado ao quadro Comportamento e Responsabilidade Individual para valorizar bons exemplos de conduta, de quem 'faz por merecer', independentemente de qualquer discussão sobre diferentes contextos sociais, culturais, ambientais, econômicos ou políticos. As imagens do programa destacam idosos se alongando e dançando com o professor, assim como um casal de idosos se beijando.

Voz da repórter Ana: 'Longevidade. Digamos que seja aquele a mais que a vida te dá quando se faz por merecer'.

Voz de Ana: Na dança da vida, tem gente que vai no ritmo do trabalho, na cadência dos filhos e acaba se esquecendo do próprio ritmo. Para esse grupo, 'é hora de se cuidar'.

Voz de Ana: O seu Álvaro é casado com a dona Maria de Lurdes. Longevidade para eles! Pro sentimento que sustenta essa relação.

Álvaro: Depois de aposentado, 'eu tive uma vida 
meio sedentária, e aí a minha esposa começou a frequentar o clube da longevidade' e insistindo, insistindo, aí eu acabei vindo pra a caminhada, depois pra a dança.

Voz de Ana: O casamento de 43 anos dos dois agradece.

Maria de Lurdes: 'A gente tá no mesmo caminho, fazendo a caminhada, fazendo a dança, então melhorou bastante'.

Nessa edição do programa 'Bem Estar', percebe-se uma abordagem tangencial de aspectos culturais e distante de políticas públicas. Nesse sentido, a saúde do idoso se afasta da noção de bem-estar coletivo, quando associa longevidade a merecimento, ou falta de atividade física a negligência, no caso de quem usa desculpas para não se cuidar.

\section{Considerações finais}

Pensar a saúde a partir de aspectos socioculturais e ambientais é um posicionamento contra-hegemônico, que direciona a atenção para os determinantes sociais da saúde, ainda pouco explorados nos programas analisados, tais como desigualdades sociais, custo de vida, desemprego e seus impactos na saúde. Além disso, é preciso considerar a existência de diferentes fatores que afetam as condições de vida, tanto no nível individual quanto coletivo.

Se a velhice exige saber se alimentar, se exercitar, se motivar para ter uma vida ativa e produtiva, a interpretação causal leva a colocar as consequências da falta de saúde na vida de quem negligencia essas recomendações. Dessa forma, a solução apresentada para o problema nas edições analisadas dos programas 'Ser Saudável' e 'Bem Estar' está em uma atitude da pessoa idosa, na responsabilidade com o seu corpo, com o tipo de velhice que resulta de sua postura diante da vida. Embora sejam aspectos a se considerar, a velhice precisa ser entendida e abordada em sua pluralidade.

Não há dúvida de que a evolução da ciência e da tecnologia trouxe longevidade, ampliou a expectativa de vida das pessoas, melhorou a saúde, mas ainda não conseguiu distribuir universalmente a saúde. Embora o Índice de Desenvolvimento Humano (IDH) no Brasil tenha melhorado com a implantação do SUS e de programas sociais, como o Bolsa Família e o Programa Universidade para Todos (Prouni), ainda há grande desigualdade no País quando se relacionam expectativa de vida longa e saudável, renda e educação. Não é preciso recorrer às estatísticas oficiais para compreender que saúde não depende apenas de uma escolha do indivíduo.

Ao proporem, além de uma boa alimentação, a prática de atividade física para manter-se saudável, os programas sobre a saúde do idoso no 'Ser Saudável' (TV Brasil) e no 'Bem Estar' (TV Globo) não discutem a falta de espaços públicos e equipamentos para quem não pode pagar academia, nem apresenta soluções para a maioria dos brasileiros que não podem seguir os exemplos dos personagens apresentados - que investem numa alimentação balanceada e fazem exercício físico com regularidade -, nem mesmo seguir a recomendação dos especialistas para comer a cada três horas ou incluir peixes e grãos na alimentação.

À primeira vista, esse estilo de vida saudável parece tão natural que perpassa os discursos de forma persistente, sem considerar que nem todos poderão fazer essas escolhas, principalmente diante do contexto em que vivem os mais pobres. Nesse sentido, observa-se que houve o silenciamento de vozes que destoam do propósito editorial, distante da abordagem das políticas públicas e dos determinantes sociais da saúde, o que evidencia o poder de um quadro, muitas vezes implicitamente manifesto nos exemplos, argumentos e nas imagens da narrativa. 


\section{Colaboradores}

Costa MCR contribuiu para elaboração do artigo com as seguintes atividades: concepção, planejamento, análise e interpretação dos dados, bem como a revisão final do conteúdo. Santos MLR contribuiu para elaboração do artigo com as seguintes atividades: análise e interpretação dos dados; revisão crítica do conteúdo; e aprovação da versão final do manuscrito. Brotas AMP contribuiu para elaboração do artigo com as seguintes atividades: interpretação dos dados, revisão crítica do conteúdo, revisão de normas e técnicas e aprovação da versão final do manuscrito.

\section{Referências}

1. Chaimowicz F. A saúde dos idosos brasileiros às vésperas do século XXI: problemas, projeções e alternativas. Rev Saúde Pública [internet]. 1997; 31(2):184200 [acesso em 2017 fev 8]. Disponível em: http:// www.scielosp.org/pdf/rsp/v31n2/2170.

2. Instituto Brasileiro de Geografia e Estatísticas. Trabalho e rendimento [internet]. Rio de Janeiro: IBGE; 2013 [acesso em 2015 abr 15]. Disponível em: http:// www.ibge.gov.br/home/estatistica/populacao/trabalhoerendimento/pnad2013.

3. Brasil. Ministério da Saúde. Portaria no 2.528 , de 19 de outubro de 2006. Aprova a Política Nacional de Saúde da Pessoa Idosa [internet]. Diário Oficial da União. 19 Out 2006 [acesso em 2015 abr 15]. Disponível em: http://bvsms.saude.gov.br/bvs/saudelegis/ gm/2006/prt2528_19_10_2006.html. Não paginado.

4. Albuquerque MSV, Lyra TM, Farias SF, et al. Acessibilidade aos serviços de saúde: uma análise a partir da Atenção Básica em Pernambuco. Saúde debate. 2014 out [acesso em 2018 set 6]; 38(esp):182-194. Disponível em: http://www.scielo.br/pdf/sdeb/v38nspe/01031104-sdeb-38-spe-0182.pdf.
5. Cunha ABO, Vieira-da-Silva LM. Acessibilidade aos serviços de saúde em um município do Estado da Bahia, Brasil, em gestão plena do sistema. Cad. Saúde Pública [internet]. 2010 abr [acesso em 2018 set]; 26(4):725-737. Disponível em: http://www.scielo.br/ pdf/csp/v26n4/15.pdf.

6. Boing AC, Bertoldi AD, Boing AF, et al. Acesso a medicamentos no setor público: análise de usuários do Sistema Único de Saúde no Brasil. Cad. Saúde Pública [internet]. 2013 abr; 29(4):691-701. Disponível em: http://www.scielo.br/pdf/csp/v29n4/07.pdf .

7. Loyola Filho AI, Uchoa E, Firmo JOA, et al. Estudo de base populacional sobre o consumo de medicamentos entre idosos: Projeto Bambuí. Cad Saúde Pública [internet]. 2005 mar-abr [acesso em 2018 set 6]; 21(2):545-553. Disponível em: https://www.scielosp.org/pdf/csp/2005.v2ln2/545-553/pt.

8. Camacho ACLF, Coelho MJ. Políticas públicas para a saúde do idoso: revisão sistemática. Rev Bras Enferm [internet]. 2010 abr [acesso em $2017 \mathrm{fev}$ 8]; 63(2):279-284. Disponível em: http://www.redalyc. org/pdf/2670/267019594017.pdf. 
9. Martín-Barbero J. Dos meios às mediações: comunicação, cultura e hegemonia. 4. ed. Rio de Janeiro: UFRJ; 2006.

10. Debert GG. Velhice e o curso da vida pós-moderno Revista USP [internet]. 1999 jun-ago [acesso em 2014 mar 10]; 42:70-83. Disponível em: http://www.revistas.usp.br/revusp/article/view/28456/30313.

11. Lefèvre F. A saúde como fato coletivo. Saúde Soc [internet]. 1999 [acesso em 2014 ago 10]; 8(2):83-91. Disponível em: www.scielo.br/pdf/sausoc/v8n2/05.pdf.

12. Entman RM. Framing: toward clarification of a fractured paradigm. J Commun. 1993 dez; 43(4):51-58.

13. Reese SD. The Framing Project: A Bridging Model for Media Research Revisited. J Commun. 2007 fev; 57(1):148-154.

14. Van Gorp B. The constructionist approach to framing: bringing culture back. J Commun. 2007 fev; 57(1):60-78
15. Matthes J, Kohring M. The content analysis of media frames: Toward improving reliability and validity. J Commun. 2008 jul; 58(2):258-279.

16. Gamson WA, Modigliani A. Media discourse and public opinion on nuclear power: a constructionist approach. American J Sociol. 1989 jul; 95(1)1-37.

17. Entman RM. Framing: toward clarification of a fractured paradigm. J Commun. 1993 dez; 43(4):52-60.

18. Geertz C. A interpretação das culturas. Rio de Janeiro: LTC; 1989.

19. Lyotard J. A condição pós-moderna. 6. ed. Rio de Janeiro: José Olympio; 1998

Recebido em 15/07/2018

Aprovado em 14/09/2018

Conflito de interesses: inexistente

Suporte financeiro: não houve 